\title{
Serum-insulin Changes Following Administration of L-Leucine to Children
}

\author{
D. B. GRANT \\ From the Institute of Child Health, London W.C.1
}

There have been many published accounts of idiopathic leucine-sensitive hypoglycaemia of infancy since its description by Cochrane, Payne, Simpkiss, and Woolf in 1956, and raised plasmainsulin levels after the administration of L-leucine have been found in children with this condition (DiGeorge, Auerbach, and Mabry, 1960; Grumbach and Kaplan, 1960; Harmer and Sinclair, 1964). Similar changes in insulin have been found in patients with islet-cell tumours (Floyd, Fajans, Knopf, and Conn, 1964) and in healthy subjects pretreated with sulphonylurea drugs (Floyd, Fajans, Knopf, and Conn, 1963). Smaller increases in plasma-insulin after leucine administration have been reported in normal subjects (Floyd et al., 1963), and it has been suggested that the effect of L-leucine on plasma-insulin in idiopathic leucine-sensitive hypoglycaemia is an exaggeration of a normal phenomenon (Fajans, 1965).

Changes in blood sugar after a leucine load may be difficult to interpret in children with persistent, severe hypoglycaemia, even when control tests without leucine are carried out, and in these cases the measurement of serum-insulin may help in establishing a diagnosis of leucine-sensitive hypoglycaemia. There is, however, little information available on the size of increase in serum-insulin which can be expected after the administration of leucine to leucine-insensitive children.

This paper describes the serum immunoreactive insulin changes observed during leucine tolerance tests which were carried out in 28 children who had been admitted to hospital for investigation of either mental retardation or hypoglycaemia.

\section{Patients and Methods}

Of the 28 children studied, 21 suffered from mental retardation for which no biochemical cause was found. The ages of these children varied from 9 months to $9 \frac{1}{4}$ years and the weights of 5 of them lay on or below the 3rd centile (Tanner, 1958).

Received May 9, 1967.
A further 4 children, aged between $1 \frac{1}{2}$ and $7 \frac{1}{2}$ years, suffered from intermittent hypoglycaemia after an overnight fast. The weight of one of these children lay below the 3 rd centile.

In the remaining 3 children a diagnosis of idiopathic leucine-sensitive hypoglycaemia was made either during a previous admission to hospital or on the results of the leucine tolerance tests described in this paper.

Details of one of the leucine-sensitive children (Case 1), a girl aged 2 years and 10 months, have been published elsewhere (Grant, Piesowicz, and Buckler, 1966). The second leucine-sensitive child (Case 2), a girl aged 4 years, was admitted to hospital for reassessment of her treatment with corticosteroids. Her symptoms began at the age of 8 months when she began to have convulsions associated with severe hypoglycaemia. The diagnosis of leucine-sensitive hypoglycaemia was not established until she was $2 \frac{1}{2}$ years old. At the time of study she had been treated with a restricted leucine diet for 18 months and with corticosteroids for over 3 years. Case 3, a boy of 7 years, had less marked symptoms than the other 2 children. At the age of 5 months he was noted to be having attacks of pallor and drowsiness, but a diagnosis of leucine-sensitive hypoglycaemia was not made until he was 4 years old. At this age his dietary leucine was restricted and his symptoms were almost completely controlled. At the time of study he had been admitted for reassessment of his diet as his parents had noticed that he could tolerate food with a high leucine content. Pancreatic biopsy was performed on only Case 3: this showed no evidence of islet-cell hyperplasia.

All the children were given oral L-leucine $(0 \cdot 15 \mathrm{~g} . / \mathrm{kg}$. body weight) as a slurry in $0.01 \%$ dioctyl sodium sulphosuccinate. Leucine was given to 2 leucine-sensitive children and 8 mentally retarded children 3 hours after a low-leucine breakfast and to one leucine-sensitive child (Case 1) 3 hours after a milk feed. The remaining children were given leucine after an overnight fast. Two baseline capillary blood specimens were obtained by fingerprick and then further samples were collected $15,30,45,60$, and 120 minutes after leucine had been given. Control tests without leucine were not performed.

Blood sugar was measured by a modification of the method of Folin and Wu (Wilkinson, 1960). In the present study, the standard deviation for the paired 
fasting specimens about their means was $\pm 5 \cdot 3 \%$ and blood sugar changes of less than $12 \%$ cannot be considered significant. Serum-insulin was measured by a modification of the radioimmunoassay of Morgan and Lazarow (1963). Details of the assay have been given elsewhere (Grant, 1967). The lowest concentration of insulin which can be measured with confidence in this assay lies between 2 and $3 \mu \mathrm{U} / \mathrm{ml}$. and insulin changes of less than $3 \mu \mathrm{U} / \mathrm{ml}$. cannot be considered significant. In the present study, serum-insulin levels of less than $3 \mu \mathrm{U} / \mathrm{ml}$. were assigned the value obtained in the assay. The standard deviation for the paired fasting values about their means was $\pm 1 \mu \mathrm{U} / \mathrm{ml}$.

\section{Results}

Children with mental retardation or intermittent fasting hypoglycaemia. In the tests in which leucine was given after an overnight fast, the fasting blood sugar values ranged from 69-120 mg./100 ml. (mean $87 \mathrm{mg} . / 100 \mathrm{ml}$.). The percentage changes in blood sugar after leucine are shown in Fig. 1. In 7 children a rise of more than $12 \%$ and in 6 children a fall of more than $12 \%$ was found in at least one specimen taken during the first hour after leucine. Two children showed decreases of $40 \%$ and $45 \%$ in single specimens.

The fasting serum-insulin values ranged from 0 to $8 \mu \mathrm{U} / \mathrm{ml}$. (mean $3 \mu \mathrm{U} / \mathrm{ml}$.). The insulin changes after leucine are shown in Fig. 2. Insulin increments greater than $3 \mu \mathrm{U} / \mathrm{ml}$. were found in 7 children. Two children showed increments greater

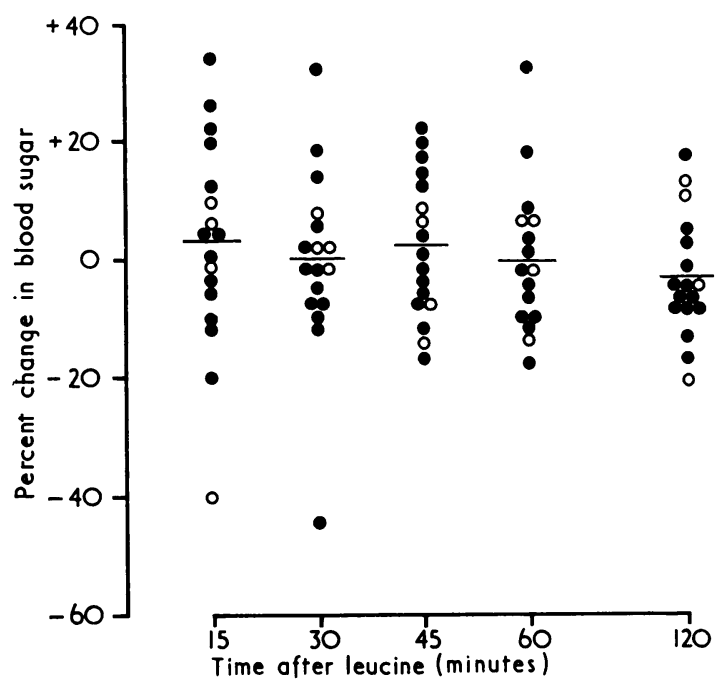

FIG. 1.-Percentage change in blood sugar following the administration of L-leucine after an overnight fast. Cases of mental retardation. O Cases of fasting hypoglycaemia. than $5 \mu \mathrm{U} / \mathrm{ml}$., which coincided exactly with increases in blood sugar of more than $12 \%$. There was no appreciable change in serum-insulin in the two children who showed the most marked fall in blood sugar. The correlation coefficient calculated for the results for all the children during the first hour after leucine showed a significant correlation between blood sugar and insulin $(r=0.307$; $\mathrm{p}<0 \cdot 02)$.

The blood sugar and serum-insulin values which were obtained when leucine was given 3 hours after a low-leucine breakfast are given in Table I. In 5 tests there was poor agreement between the paired baseline values, indicating that a steady state had not been reached at the beginning of the test. In one child, there was little change in serum-insulin after leucine was given, in 5 children there was a progressive fall in insulin, and in 2 children increases of 27 and $9 \mu \mathrm{U} / \mathrm{ml}$., coinciding exactly with increases in blood sugar, were observed.

On the evidence of the blood-sugar changes which were observed during these tolerance tests, it was concluded that none of the children was leucinesensitive.

Leucine-sensitive children. 6 leucine tolerance tests were carried out on the 3 leucine-sensitive children. The results are given in Table II. Two of the tests were terminated after 30 minutes because of symptoms of hypoglycaemia. In all of the tests an increase in serum-insulin was observed 15 or 30 minutes after leucine had been given. The maximum insulin increase in each test ranged from $23-57 \mu \mathrm{U} / \mathrm{ml}$. With the exception of one test on Case 2, which was carried out while she was being treated with cortisone acetate, the

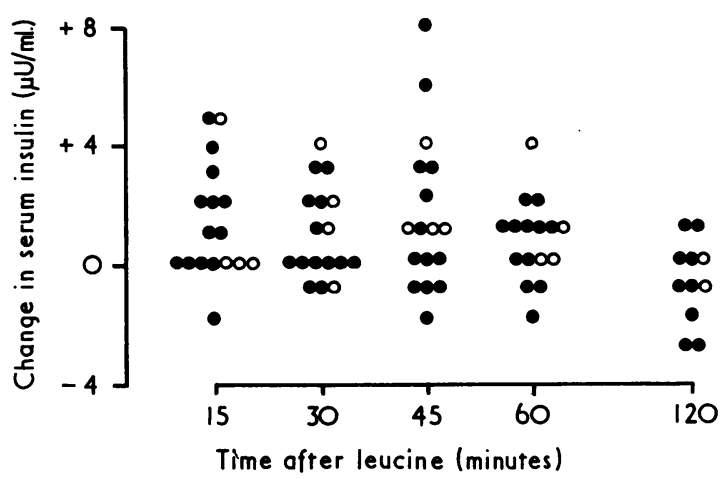

FIG. 2.-Serum-insulin changes following the administration of L-leucine after an overnight fast. - Cases of mental retardation. O Cases of fasting hypoglycaemia. 
TABLE I

Serum-insulin and Blood-sugar Values $(\mu \mathrm{U} / \mathrm{ml}$.) in 8 Mentally Retarded Children

\begin{tabular}{|c|c|c|c|c|c|c|c|}
\hline \multirow{2}{*}{$\begin{array}{l}\text { Subject } \\
\text { No. }\end{array}$} & \multicolumn{7}{|c|}{ Time (min.) from Leucine Load } \\
\hline & -30 & -5 & +15 & +30 & +45 & +60 & +120 \\
\hline $\begin{array}{l}1 \\
2 \\
3 \\
4 \\
5 \\
6 \\
7 \\
8\end{array}$ & $\begin{array}{r}15(96) \\
44(121) \\
18(115) \\
14(98) \\
\frac{1}{2}(104) \\
12(79) \\
4(90) \\
4(95)\end{array}$ & $\begin{array}{r}32(123) \\
21(109) \\
9(117) \\
17(98) \\
6(118) \\
11(95) \\
25(103) \\
10(93)\end{array}$ & $\begin{array}{r}10(91) \\
8(109) \\
36(150) \\
14(102) \\
4(110) \\
6(82) \\
12(110) \\
8(100)\end{array}$ & $\begin{array}{rr}11 & (61) \\
6 & (89) \\
34 & (130) \\
9(109) \\
7(111) \\
2(88) \\
9(79) \\
8(134)\end{array}$ & $\begin{array}{r}5(64) \\
5(91) \\
9(97) \\
10(102) \\
15(138) \\
2(85) \\
5(67) \\
2(124)\end{array}$ & $\begin{array}{r}6(73) \\
4(92) \\
7(92) \\
17(98) \\
12(120) \\
0(90) \\
6(79) \\
3(121)\end{array}$ & $\begin{array}{rr}5 & (87) \\
\frac{2}{2}(89) \\
6(85) \\
5(109) \\
5 \quad(79) \\
=\quad(84) \\
4 \quad(88)\end{array}$ \\
\hline
\end{tabular}

Leucine given 3 hours after low-leucine breakfast.

Blood-sugar values are shown in parentheses.

TABLE II

Serum-insulin and Blood-sugar Values $(\mu \mathrm{U} / \mathrm{ml}$.) in 3 Leucine-sensitive Children

\begin{tabular}{|c|c|c|c|c|c|c|}
\hline \multirow{2}{*}{ Case } & \multicolumn{6}{|c|}{ Time (min.) from Leucine Load } \\
\hline & -30 & -5 & +15 & +30 & +45 & +60 \\
\hline $\begin{array}{l}1 \\
1 \star \\
2 \dagger \\
2 \ddagger \\
2 \ddagger \\
3\end{array}$ & $\begin{array}{l}19(50) \\
28(40) \\
22(80) \\
10(78) \\
26(99) \\
23(97)\end{array}$ & $\begin{array}{r}16(46) \\
15(37) \\
14(71) \\
9(72) \\
13(91) \\
7(91)\end{array}$ & $\begin{array}{l}63(25) \\
12(30) \\
47(87) \\
55(50) \\
52(59) \\
10(91)\end{array}$ & $\begin{array}{l}63(25) \\
72(20) \\
48(62) \\
31(42) \\
37(57) \\
30(84)\end{array}$ & $\begin{array}{l}56(27) \\
\frac{43}{43}(57) \\
53(59) \\
29(62)\end{array}$ & $\begin{array}{l}\frac{58}{6}(22) \\
\frac{61}{27}(62) \\
14(61) \\
(62)\end{array}$ \\
\hline
\end{tabular}

* While receiving chlorothiazide $(200 \mathrm{mg}$. /day).

$\dagger$ While receiving cortisone acetate $(20 \mathrm{mg}$./day).

¥ While receiving chlorothiazide ( $300 \mathrm{mg}$./day).

Leucine given 3 hours after low-leucine breakfast (Cases 2, 3) or milk feed (Case 1).

Blood-sugar values are shown in parentheses.

rise in insulin was accompanied by a fall in blood sugar. The smallest and least well-sustained rise in insulin was found in the child with the least severe symptoms.

\section{Discussion}

The variable blood sugar changes found in the leucine-insensitive children are similar to the results obtained by other workers using the same dose of leucine in normal children (Grumbach and Kaplan, 1960; Loeb, Rasio, and Conard, 1965). They contrast with the small but significant decreases in blood sugar which DiGeorge, Auerbach, and Mabry (1963) observed in normal children after a larger dose of leucine $(0 \cdot 3 \mathrm{~g} . / \mathrm{kg}$.).

The results of this study indicate that, under the conditions used, L-leucine has little effect on seruminsulin in leucine-insensitive children. This finding is similar to the observations of Yalow and Berson (1960) in 3 control subjects and differs from the results of Floyd et al. (1963) who described greater plasma-insulin increments in a selected group of normal adults after a slightly larger dose of intravenous leucine. The insulin increments described in this paper lie well below the increase of $30 \mu \mathrm{U} / \mathrm{ml}$. which Fajans (1965) has suggested should be taken as the upper limit of the normal response. As control tests without leucine were not performed in this study, the small insulin increases which were noted cannot be attributed to the administration of leucine, and the correlation which was found between a rise in insulin and a rise in blood sugar suggests that other factors may have been responsible for the changes that were observed.

The poor agreement found between paired 'baseline' values when leucine was given after a 3-hour fast illustrates a problem that may be encountered when such tests are performed after short periods of fasting. However, even under these conditions, the insulin changes appear to distinguish clearly between the children with leucine-sensitive hypoglycaemia and the leucineinsensitive children.

While a marked increase in insulin after leucine 
has been described in a number of children with idiopathic leucine-sensitive hypoglycaemia, this finding has not been an invariable one (DiGeorge et al., 1960). Greenberg and Reaven (1966) found evidence that leucine inhibited gluconeogenesis in mouse liver in vitro, and they suggested that the effect of leucine in children with hypoglycaemia might be non-specific and largely dependent on other factors which regulate blood sugar. By basing the diagnosis of leucine-sensitive hypoglycaemia on the insulin changes after a leucine load, the diagnosis has been modified to one of 'leucine-induced hyperinsulinism and hypoglycaemia'. This modification of the diagnosis may not be justified as the aetiology of leucine-sensitive hypoglycaemia is still uncertain. However, it seems likely that the measurement of serum-insulin during leucine tolerance tests may help to determine whether the condition is a heterogeneous one.

\section{Summary}

Serum immunoreactive insulin was measured during leucine tolerance tests in 28 children with mental retardation or hypoglycaemia. Little change in serum-insulin was found in 25 leucine-insensitive children. Insulin increments of 23-57 $\mu \mathrm{U} / \mathrm{ml}$. were observed in 3 children with leucine-sensitive hypoglycaemia. The relevance of serum-insulin measurement in the diagnosis of leucine-sensitive hypoglycaemia is discussed.

I wish to thank the physicians of The Hospital for Sick Children, Great Ormond Street, for allowing me to study their patients, and Dr. B. E. Clayton for her encouragement and advice.
This work was supported by a grant from the Medical Research Council.

\section{REFERENCES}

Cochrane, W. A., Payne, W. W., Simpkiss, M. J., and Woolf, L. I. (1956). Familial hypoglycemia precipitated by amino acids. f. clin. Invest., 35, 411 .

DiGeorge, A. M., Auerbach, V. H., and Mabry, C. C. (1960). Elevated serum insulin associated with leucine-induced hypoglycaemia. Nature (Lond.), 188, 1036.

$\longrightarrow$ - - and - (1963). Leucine-induced hypoglycemia. III. The blood glucose depressant action of leucine in normal individuals. F. Pediat., 63, 295.

Fajans, S. S. (1965). Leucine-induced hypoglycemia. New Engl. F. Med., 272, 1224.

Floyd, J. C., Jr., Fajans, S. S., Knopf, R. F., and Conn, J. W. (1963). Evidence that insulin release is the mechanism for experimentally induced leucine hypoglycemia in man. $\mathcal{f}$. clin. Invest., 42, 1714.

$\longrightarrow$, and - (1964). Plasma insulin in organic hyperinsulinism. F. clin. Endocr., 24, 747.

Grant, D. B. (1967). Fasting serum insulin levels in childhood. Arch. Dis. Childh., 42, 375.

—, Piesowicz, A. T., and Buckler, J. M. H. (1966). Effect of treatment with diazoxide and chlorothiazide on a child with leucine-sensitive hypoglycaemia. Brit. med. F., 2, 1494.

Greenberg, R., and Reaven, G. (1966). The effect of L-leucine on hepatic glucose formation. Pediatrics, 37, 934.

Grumbach, M. M., and Kaplan, S. L. (1960). Amino acid and alphaketo acid-induced hyperinsulinism in the leucine-sensitive type of infantile and childhood hypoglycemia. $\mathcal{F}$. Pediat., 57, 346.

Harmer, C., and Sinclair, L. (1964). Leucine-sensitive hypoglycaemia. Proc. roy. Soc. Med., 57, 119

Loeb, H., Rasio, E., and Conard, V. (1965). Étude chez l'enfant de la sensibilisation à la leucine par le chlorpropamide. Rev. franc. Etud. clin. biol., 10, 423.

Morgan, C. R., and Lazarow, A. (1963). Immunoassay of insulin: two antibody system. Diabetes, $12,115$.

Tanner, J. M. (1958). Standards for growth of normal children. In Modern Trends in Paediatrics, 2nd Series, ed. A. Holzel and J. P. M. Tizard, p. 330 . Butterworth, London.

Wilkinson, R. H. (1960). Chemical Micromethods in Clinical Medicine, p. 68. Thomas, Springfield, Illinois; Blackwell, Oxford.

Yalow, R. S., and Berson, S. A. (1960). Immunoassay of endogenous plasma insulin in man. $\mathcal{F}$. clin. Invest., 39, 1157. 